\title{
Condições Climáticas em Juazeiro do Norte - CE: A Formação de Ilha de Calor
}

\author{
Guilherme Lemos Francal
}

\begin{abstract}
Resumo: A expansão urbana gera novas condições geográficas e climáticas, pois reduz a evaporação e a dispersão de poluentes, e, aquece o ar, formando Ilhas Urbanas de Calor. O município de Juazeiro do Norte - CE possui intensa atividade urbana e industrial favorecendo o desenvolvimento do fenômeno. $\mathrm{O}$ estudo buscou identificar o desenvolvimento de Ilhas de Calor Urbanas, suas causas e consequências na cidade. Foi desenvolvido um estudo de caso, com abordagem, observacional, descritiva, para registrar, analisar e relacionar os eventos ou fenômenos. Os dados foram coletados em outubro de 2013 e analisados segundo os perfis térmicos, estrutura, ocupação e atividade urbana, para compor o perfil climático. Os resultados iniciais demonstraram diferenças de temperatura significativas das zonas urbanas, pelas alterações do espaço e do solo, aumento populacional e do fluxo de veículos na zona urbana. Estudos sobre clima urbano devem considerar as características do solo, ocupação, vegetação, recursos hídricos e meios de transportes. Um planejamento urbano ineficaz origina uma problemática ambiental, ocasionando o aparecimento de processos erosivos, desequilíbrio socioambiental e aumento da poluição.
\end{abstract}

Palavras-chaves: Clima Urbano. Ilhas de Calor. Perfil Térmico.

\section{Weather Conditions in Juazeiro do Norte - CE: The Formation of Heat Island}

\begin{abstract}
Urban sprawl creates new geographical and climatic conditions, it reduces evaporation and dispersion of pollutants, and heats the air, forming Urban Heat Islands. The municipality of Juazeiro do Norte - CE has intense urban and industrial activity favoring the development of the phenomenon. The study sought to identify the development of Urban Heat Islands, its causes and consequences in the city. A case study was developed with approach, observational, descriptive, to record, analyze and relate the events or phenomena. Data were collected in October 2013 and analyzed according to the thermal profiles, structure, occupation and urban activity, to compose the climatic profile. Initial results showed significant differences in temperature of urban areas, the changes of space and soil, population growth and the flow of vehicles in the urban area. Studies on urban climate should consider soil characteristics, occupation, vegetation, water resources and means of transport. An ineffective urban planning gives an environmental problem, causing the onset of erosion, environmental imbalance and increased pollution.
\end{abstract}

Keywords : Urban Climate. Heat Islands. Thermal Profiling.

\section{Introdução}

As modificações ocorridas no espaço socioambiental decorrentes da intensa atividade urbana demarcaram novas condições geográficas e climáticas em todo o ambiente.

\footnotetext{
${ }^{1}$ Licenciatura Plena em Geografia pela Universidade Federal do Ceará. Pós Graduação Lato Sensu em Geografia e o Meio Ambiente pela Universidade Regional do Cariri - URCA. E-mail para contato: gui725@ hotmail.com
} 
Atualmente, os núcleos urbanos vêm sofrendo as consequências da deficiente organização espacial e do uso errôneo de modelos de desenvolvimento nos moldes da economia capitalista-industrial com consequentes alterações climáticas urbanas.

Um fenômeno característico desse processo de expansão e aglomeração citadina é o aquecimento do ar nos centros urbanos em relação ao espaço rural. As cidades em desequilíbrio funcional ou estrutural apresentam alta concentração de ar quente, acontecimento que reduz a evaporação e dispersão de poluentes, determinando uma condição climática que fora nomeada de Ilha de Calor.

Diversos fatores estimulam o aparecimento, intensidade e a distribuição das Ilhas de Calor, dos quais se destacam a área da cidade, número de habitantes, período do dia, estação do ano e, o tipo e forma de ocupação do solo. Essas características urbanas são agravadas pela a interação com os materiais empregados nas construções; a diminuição das áreas naturais de transpiração; o aumento da poluição atmosférica e o mau planejamento urbano, determinando o desenvolvimento desse fenômeno climático.

A capacidade de adequação do espaço urbano às atividades humanas é levada ao limite da adaptação diária. A produção abusiva de resíduos do metabolismo socioeconômico urbano prejudica a integração do ambiente ao desenvolvimento da urbe, imputando-lhe mais celeridade e adequação do que ele pode assimilar.

A implantação de modelos urbanos de desenvolvimento sustentável deve adequar, da forma mais equilibrada possível, a sobrevivência humana à utilização dos sítios urbanos, de maneira apropriada aos espaços geográficos. Ações que promovam a organização das linhas de entrada e saída de resíduos urbanos, podem ser um caminho viável para o progresso e sucesso ambiental, reduzindo ou eliminando malefícios no cotidiano das urbes, gerando estabilização quantos a condição humana e ambiental.

Pensando nisso, o emprego de meios práticos que indiquem a melhor forma para a ocupação urbana ou a presença do fenômeno em determinada região podem permitir o saneamento das condições desfavoráveis. Ou ainda, impedir o agravamento, principalmente, em cidades ou regiões de pequeno e médio porte, em crescente desenvolvimento, mas que ainda não apresentam as inúmeras mazelas socioambientais que podem inibir soluções viáveis e rápidas aos desequilíbrios constatados. 
Deste modo, considerando as principais condições para o desenvolvimento do fenômeno climático Ilha de Calor, objeto desse estudo, foi analisado o núcleo urbano da cidade de Juazeiro do Norte - CE, situada no interior cearense, na região do Cariri (Oásis do Sertão), com fauna e flora abundante em um terreno cristalino e fértil. A urbe possui área de $248,558 \mathrm{~km}^{2}$, intensa atividade urbana, industrial e demográfica.

A cidade apresenta constante crescimento demográfico, espacial, econômico e social, tornando-se possuidora das características que concernem à possibilidade de fundamentar teoricamente e constatar empiricamente as condições favoráveis ao desenvolvimento da Ilha Urbana de Calor.

Dessa forma, o presente estudo buscou identificar o desenvolvimento do fenômeno Ilha de Calor e suas consequências para a cidade de Juazeiro do Norte - CE. De forma mais específica, investigar as possíveis causas para o aparecimento do fenômeno, perfis térmicos das zonas periféricas e central, e medidas cabíveis para eliminar ou reduzir os desequilíbrios que propiciam o aparecimento do fenômeno.

\section{Referencial Teórico}

As mudanças causadas pelas alterações ambientais nas últimas décadas geram incertezas sobre o futuro do planeta. Os inúmeros estudos mundiais realizados sobre o peso da ação humana no desequilíbrio climático e ambiental alertam para o desafio de estabilizar o crescimento humano permitindo o desenvolvimento econômico e social, de forma sustentável na utilização e conservação dos recursos disponíveis.

Regionalmente, impactos no nível natural dos espaços físicos ocupados estão relacionados aos aspectos culturais e estruturais dos núcleos urbanos. Isso porque, para Vidal de La Blache, a região é um algo palpável, vivo, individual, demarcado e definido pelo relacionamento humano-ambiental, apresentando uma paisagem resultante da sobreposição das influências humanas e naturais (SCHIER, 2003).

As atividades humanas sejam econômicas, sociais ou culturais marcam os espaços físicos, determinando condições ambientais diretamente proporcionais às ações desempenhadas na vida diária. O resultado dessa interação é adsorvido pelo ambiente e expressado continuamente. 
Id on Line Revista Multidisciplinar e de Psicologia

Id on Line Multidisciplinary and Psycology Journal

Nesse sentido, o homem transforma o meio natural introduzindo uma identidade urbana. Além disso, alguns núcleos urbanos possuem maior demografia, economia e influência social em relação a outros, originando a Macrocefalia Urbana ${ }^{1}$, determinada pelo excesso de atividades e pessoas em um espaço limitado. Tal condição, antes ligada a amplos centros urbanos (metrópoles), como São Paulo, Rio de Janeiro e Salvador, hoje, já existe em cidades de porte médio, com papéis altamente centralizados em relação às cidades e região sob sua influência direta (SILVA; COELHO, 2006).

Dessa forma, a interação desses centros humanos, nos diferentes níveis geográficos, é responsável pelas transformações globais, o que pode gerar benefícios, como desenvolvimento comercial, industrial e educacional, e, malefícios, como diminuição de áreas verdes e esgotamento do solo, entre outros.

Uma estrutura macrocefálica gera implicações urbanas e, invariavelmente, desencadeia problemas ambientais, como poluição do ar e água, estresse urbano e grandes alterações térmicas, além da dificuldade na administração dos resíduos do metabolismo sócioeconômico-ambiental do cotidiano (ALCOFORADO, et al., 2007).

As principais mudanças climáticas encontradas derivam da desestruturação dos espaços ocupados, intensa emissão e concentração de gases poluentes na atmosfera, entre ele os responsáveis pelo efeito estufa, tais como: Dióxido de Carbono $\left(\mathrm{CO}_{2}\right)$, Metano $\left(\mathrm{CH}_{4}\right)$, Óxido Nitroso $\left(\mathrm{N}_{2} \mathrm{O}\right)$, Hidrofluorcarbonos (HFCs), Perfluorcarbonos (PFCs) e o Hexafluoreto de Enxofre (SF6) (MAY; LUSTOSA; VINHA, 2003).

No período pré-industrial o teor de $\mathrm{CO}_{2}$ atmosférico era de 288 ppm $^{2}$, e em 2005 subiu para 378,9 ppm. O aumento de cerca de $30 \%$ é alarmante por ser o principal gás na retenção de calor, forte indicador da intensa atividade humana, decorrente da queima de combustíveis fósseis, como o petróleo e o carvão, e do desmatamento causando efeitos em todos os níveis urbanos (BURALI, 2007 apud SCHEIN, 2006).

Estruturar os núcleos urbanos, principalmente os de maior desenvolvimento socioeconômico, de forma a transformar em espaços urbano-ambientais equilibrados, minimizando impactos externos proporcionalmente a qualidade de vida dos citadinos, pode não

\footnotetext{
${ }^{1}$ Consequência da urbanização, onde a população se transfere de maneira acelerada, desorganizada e descapitalizada para a cidade, sem tempo de implantar uma estrutura distribuída, gerando a concentração que manifesta a macrocefalia. Disponível em: <http://g1.globo.com/Noticias/Vestibular/0,,MUL1452828-5604,00-ENTENDA+0+QUE+E+MACROCEFALIA+URBANA.html,acesso>: em 08 abr 2013.

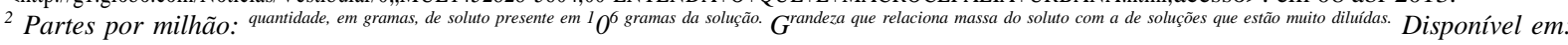
http://www.brasilescola.com/quimica/partes-por-milhao-ppm.htm, acesso em 06/04/2013.
} 
Id on Line Revista Multidisciplinar e de Psicologia

Id on Line Multidisciplinary and Psycology Journal

ser mera utopia, se considerada ações de planejamento complexas e indispensáveis para evitar condições desfavoráveis, como o aparecimento de Ilhas Urbanas de Calor (ALCOFORADO et al., 2007, p.593 apud MILLS, 2006).

\section{Juazeiro do Norte - CE: Características Gerais.}

O município de Juazeiro do Norte situa-se na Região Metropolitana do Cariri, criada em 2009, da qual fazem parte mais oito municípios, são eles: Crato, Barbalha, Missão Velha, Caririaçu, Farias Brito, Nova Olinda, Santana do Cariri e Jardim. A cidade é limitada, geograficamente, ao norte, com Caririaçu; ao sul, com Barbalha; a leste, com Missão Velha e a oeste, com Crato. A integração do município de Juazeiro do Norte com os circunvizinhos, Crato e Barbalha, forma a conurbação Crajubar, como pode ser observado na figura 1 (IBGE, 2012).

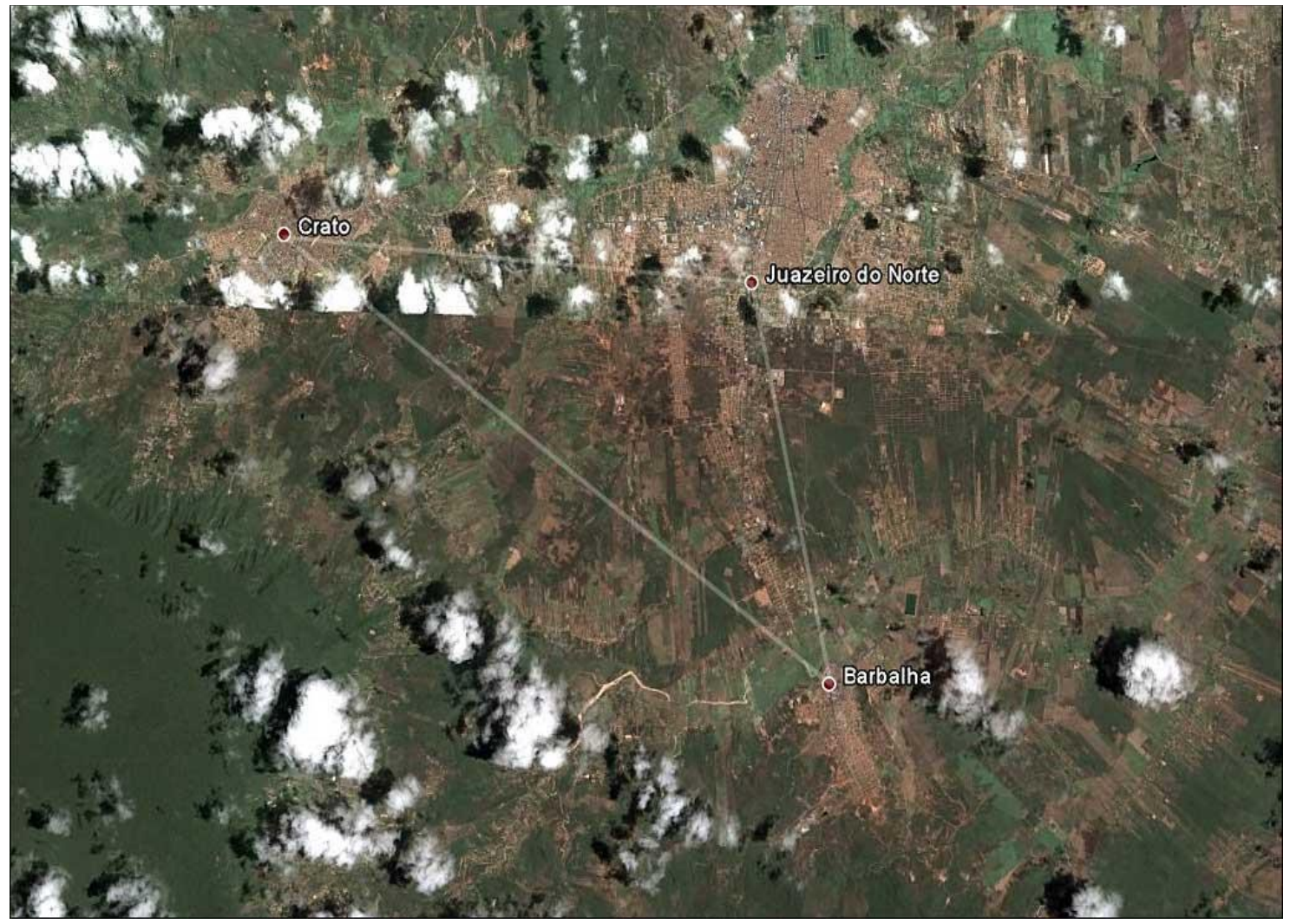

Figura 1: Traçado da Conurbação Crajubar (imagem de satélite).

Fonte: Notícia e Desenvolvimento. Disponível em: http://noticiaedesenvolvimento.blogspot.com.br/2012_01_01_archive.html, acesso em 06/04/2013. 
Id on Line Revista Multidisciplinar e de Psicologia

Id on Line Multidisciplinary and Psycology Journal

Juazeiro do Norte localiza-se no sul do estado do Ceará, a $533 \mathrm{~km}$ da capital Fortaleza. Possui área de 248,558 km² altitude média de 377,3 m, taxa de urbanização de 95,3\% e população de 255648 habitantes, fazendo do município o terceiro mais populoso, maior do interior cearense e centésimo maior do Brasil. A cidade possuir 34 bairros, como disposto na Figura 2 (IBGE, 2012).

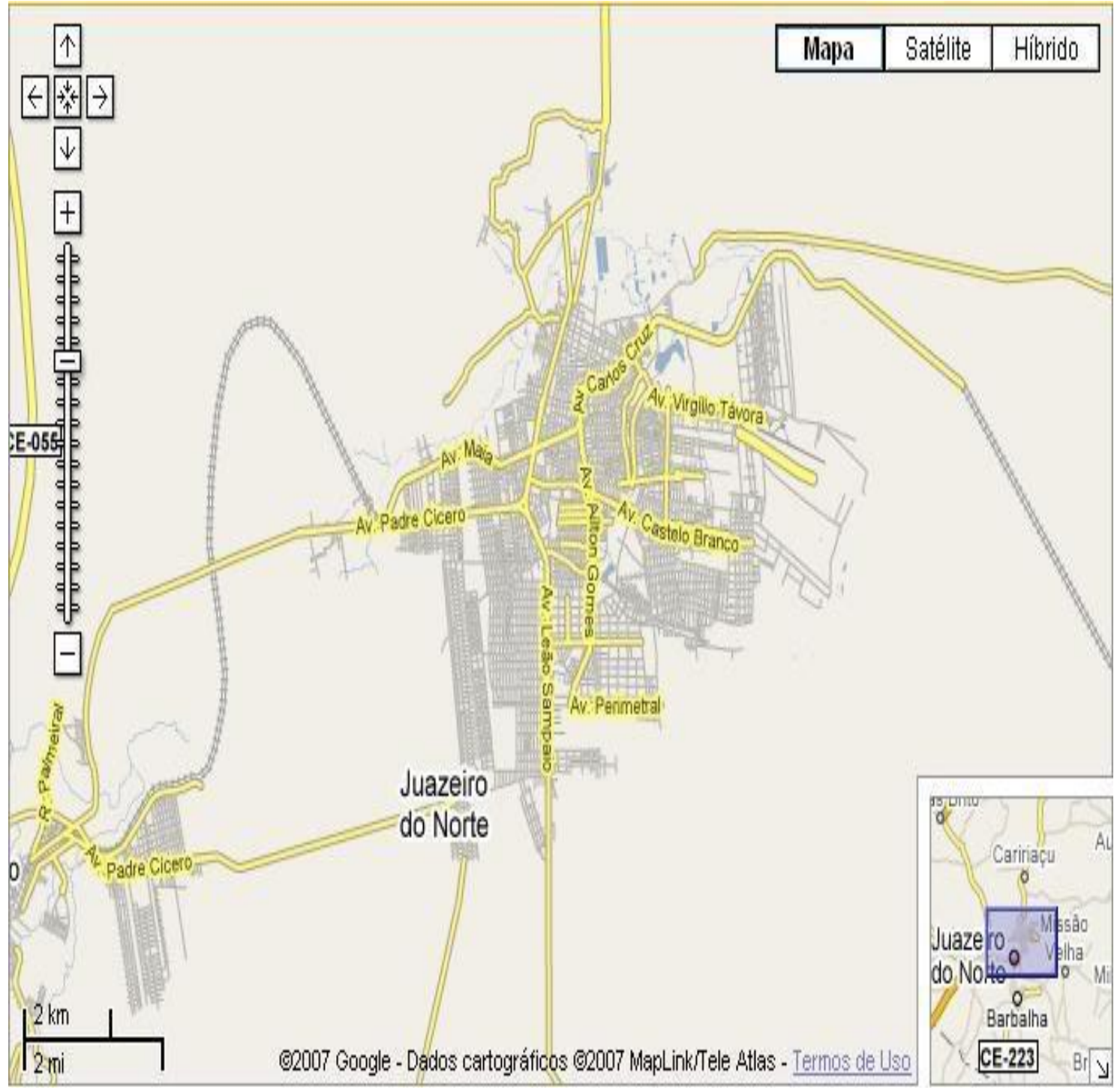

Figura 2: Mapa da cidade de Juazeiro do Norte (imagem de satélite).

Fonte: Google Mapas (2007). Disponível em: http://www.skyscrapercity.com/showthread.php?t=553109, acesso em 06/04/2013.

O nome Juazeiro adotado em 1943 é de origem tupi-português, onde "juá" ou "iuá" significa fruto de espinho e o sufixo "eiró" refere-se à árvore típica da região, Zizyphus joazeiro. A cidade situa-se em um vale na Chapada do Araripe, com índice anual pluviométrico 
Id on Line Revista Multidisciplinar e de Psicologia

Id on Line Multidisciplinary and Psycology Journal

de $925 \mathrm{~mm}$, temperaturas entre $19^{\circ} \mathrm{C}$ a $35^{\circ} \mathrm{C}$, com médias mensais entre $24^{\circ} \mathrm{C}$ e $28^{\circ} \mathrm{C}$, terras férteis, clima semiárido, vegetação de floresta caducifólia espinhosa, pontos de transição, mata de galeria na margem dos rios Salgadinho e Carás, piscicultura no Açude Manuel Balbino e não possui grandes propriedades rurais. O relevo é regular, excetuando a Serra do Horto e a depressão entre os bairros Timbaúbas e Limoeiro. A vegetação urbana se limita às praças e parques, com principal área verde o Parque Ecológico das Timbaúbas, visando à preservação de mananciais hídricos locais e o lazer da população (LIMA; RIBEIRO, 2005).

Economicamente é um importante centro comercial e de serviços com um PIB de R \$ 1.595.504, tornando-se a quinta maior economia do Ceará, atrás de Fortaleza, Maracanaú, Caucaia e Sobral. O setor terciário é o principal setor econômico com79,93\% do PIB municipal (IPECE, 2012).

Os principais pontos comerciais são: lojas do centro da cidade, Cariri Shopping, mercados populares e uma grande rede de supermercados, vinculada a grupos, como Carrefour, Walmart e o Pão de Açúcar, com vendas no atacado e varejo, atraindo consumidores de municípios e estados vizinhos. Além disso, a rede bancária possui agências dos principais bancos (CDL, 2013).

No setor industrial destaca-se: o polo calçadista como maior do Norte/Nordeste e terceiro do país; têxtil e de máquinas de costura; folheados, com produção de joias e semijoias com parte da mão-de-obra dos internos da Penitenciária Industrial Regional do Cariri; artesanato; bebidas, e, construção civil (LOPES, 2011).

O turismo religioso conta com uma infraestrutura ampla de hotéis, pousadas e restaurantes. O Aeroporto Regional do Cariri situado em Juazeiro possui capacidade para cem mil passageiros anuais e quatro empresas aéreas (Gol, Avianca, Azul, Passaredo). O Terminal Rodoviário Interestadual possui diversas empresas com embarques diários para vários destinos do país. No transporte de cargas há inúmeras empresas e o trem da Companhia Ferroviária do Nordeste. No transporte de pessoas, conta com empresas de ônibus (Viação São Francisco, Via Metro, Viação Lobo e Expresso Bom Jesus do Horto); transportes alternativos; metrô do Cariri; moto-táxis e táxis (PREFEITURA MUNICIPAL DE JUAZEIRO, 2013).

A cidade possui duas rodovias estaduais, a CE-292 e a CE-060, e um tráfego de veículos intenso ocasionando engarrafamentos ou falta de vagas para estacionamento. As ruas do centro, já não comportam adequadamente o fluxo de veículos. Além disso, nas romarias, 
Id on Line Revista Multidisciplinar e de Psicologia

Id on Line Multidisciplinary and Psycology Journal

milhares de romeiros, seus caminhões e os comerciantes tomam as ruas da cidade. Na tentativa de permitir um rápido deslocamento dentro da cidade, alívio às ruas e acesso aos municípios vizinhos visa-se construir um Anel Viário, orçado em cerca de 90 milhões de reais, com um percurso de aproximadamente 43 quilômetros (CELESTINO, 2011).

A cidade apresenta um rápido processo de verticalização central e periférica. $O$ esgotamento sanitário atende apenas $37,35 \%$ dos domicílios, tendo o restante seus resíduos drenados para fossas, ruas e os rios da cidade. O abastecimento de água atende 98,65\%, das residências por meio de poços profundos do Parque Ecológico, açude Padre Cícero e Manuel Balbino. (IPECE, 2012).

Juazeiro do Norte resulta da dinâmica de muitos elementos do semiárido nordestino, com morfologia e clima próprio do resultado espacial, considerando os períodos de seca, o calor das depressões interplanálticas e da ocupação dos terrenos. A influência socioeconômica caracteriza a cidade em médio porte e crescente desenvolvimento, que inicialmente contava apenas com as romarias, hoje, atrai indústrias, comércio, serviços de educação e saúde, aumentando o número de habitantes e, a ocupação do solo, estando entre o desenvolvimento econômico e os limites para utilização dos recursos naturais, evidenciando aumento nas construções e fluxos de pessoas e veículos, e impactos ambientais, como as erosões aceleradas em terrenos com déficit de urbanização (LIMA; RIBEIRO, 2012).

\section{Ilha Urbana de Calor: conceito, características e parâmetros para detecção.}

O aumento de casas, veículos, indústrias e redução de áreas verdes expõe o solo, eleva a emissão de gases e da irradiação de calor, reduz a dissipação de poluentes e circulação do ar, elevando a temperatura da periferia para o centro. Ainda, gera névoas de fuligem e poeira poluídas (TEZA; BAPTISTA, 2005 apud LOMBARDO, 1985).

A ação antrópica urbana com a instalação de empreendimentos imobiliários de alta monta, a estruturação de indústrias e ampliação do comércio desencadeiam mais do que meros benefícios econômicos e sociais. Isso porque, a falta de um planejamento adequado e a excessiva utilização dos espaços e recursos naturais ocasionam consequências desagradáveis e diretas sobre o clima de determinada localidade. 
Id on Line Revista Multidisciplinar e de Psicologia

Id on Line Multidisciplinary and Psycology Journal

Esse estresse térmico, mais concentrado nos "grandes" centros urbanos, é nomeado de Ilha Urbana de Calor e classificado segundo a intensidade, origem e dinâmica, em três tipos: Ilha de Calor de superfície, temperatura distintas na zona periférica e central; Ilha de Calor atmosférica inferior, referente ao solo; e, Ilha de Calor atmosférica superior, relacionada à atmosfera da cidade (ALCOFORADO, et al., 2007).

$\mathrm{Na}$ análise da Ilha de Calor, o clima e as características da cidade devem ser avaliados em relação ao espaço adjacente, para detectar diferenças da temperatura intraurbana geradas pelos fatores físicos da ocupação do solo (AMORIM, 2007).

Esse fenômeno climático é proporcional ao planejamento deficiente ou inexistente do núcleo urbano, afetando a saúde e o cotidiano dos citadinos devido às condições do ar, ao consumo de água e energia (ALCOFORADO, et al., 2007).

Certas particularidades devem ser consideradas como parâmetros importantes para determinar a instalação, intensidade e distribuição do fenômeno climático urbano, tais como (TEZA; BAPTISTA, 2005 apud LOMBARDO, 1985):

- Ausência de vegetação ou água disponível, reduzindo a evaporação;

- Aquecimento da zona central (radiação solar inutilizada na evaporação);

- Redução do escoamento zonal com ascensão do calor e não dissipação;

- Exposição demasiada do solo promovendo a elevação da superficial;

- Características topográficas que barram a dispersão do ar quente;

- Propriedades térmicas dos materiais das construções nas urbes, que absorvem energia durante o dia e emitem radiação em excesso à noite.

Assim, o clima urbano é produto da interposição de caracteres como capeamento do solo, material das construções, geometria e rugosidade da cidade, emissão de aerossóis e produção de calor sobre a superfície (BASANE, et al., 2011).

$\mathrm{Na}$ análise da radiação absorvida, refletida e o calor superficial emitido há o padrão de refletividade ou albedo $^{3}$ para avaliar os materiais empregados nas construções, solo, vegetação, vias de tráfego e demais superfícies. Segundo a Lei de Plank ${ }^{4}$,a medição da emissão de luz determina a temperatura e essas diferenças de emissão de calor determinam uma

\footnotetext{
3 Índice de reflexão dos raios solares, onde quanto maior a reflexão, menor será o calor acumulado. Ao atingirem a superfície, os raios solares encontram diferentes materiais que podem ser mais reflexivos ou menos. Disponível em: http://educacao.uol.com.br/disciplinas/geografia/clima-influencia-da-latitude-altitude-e-albedo.htm, acesso em 09/04/2013.

4Grandeza física, onde quanto maior a temperatura para um dado comprimento de onda, maior será a quantidade de energia emitida por um corpo negro, possibilitando a medição da emissão de luz e assim a determinação da temperatura. Disponível em: http://fisicanodiaadia.blogspot.com.br/2012/02/lei-de-planck.html, acesso em 09/04/2013.
} 
Id on Line Revista Multidisciplinar e de Psicologia

Id on Line Multidisciplinary and Psycology Journal

temperatura mais elevada no centro das cidades que apresentam o fenômeno climático (BIAS; BAPTISTA; LOMBARDO, 2003).

Segundo Teza e Baptista (2005), na identificação do fenômeno Ilha Urbana de Calor, segundo dados ASTER, em três metrópoles brasileiras, constatou-se que,

\begin{abstract}
Temperaturas de superfície maiores foram detectadas em todos os centros de todas as metrópoles, ocorrendo um decréscimo da temperatura em relação às periferias. Em todas as metrópoles foi detectado um grande adensamento de edificações no centro da cidade, com construções que são feitas de materiais que possuem características de absorver mais radiação e emitir mais calor para superfície. A topografia de quase todas as metrópoles estudadas não é favorável à dispersão de poluentes e particulados atmosféricos, fator que intensifica o fenômeno ilha urbana de calor (TEZA; BAPTISTA, 2005, p. 3918).
\end{abstract}

Além dos materiais de construção, a urbanização inadequada e a industrialização modificam as características atmosféricas, dobrando a taxa de impermeabilização, reduzindo a evaporação, evapotranspiração e infiltração do solo, alterando o deslocamento do vento e a temperatura do ar, o que gera um desequilíbrio ambiental, e risco de inundações em períodos chuvosos (BASANE, et al., 2011).

O planejamento das áreas urbanas deve visar à manutenção do equilíbrio socioambiental e o desenvolvimento de modelos sustentáveis dinâmicos que sustentem recursos e o gerenciamento dos resíduos urbanos, favorecendo o solo, vegetação, água, meios de transportes, atividades econômicas e a ocupação da área. Isso porque, as transformações urbanas materializam mudanças no panorama natural das cidades que podem potencializar a problemática ambiental (HONORATO; ANDRADE, 2012).

A avaliação dos perfis térmicos, dos índices de umidade relativa do ar, da termografia e ocupação das áreas, podem ser realizadas de acordo com medições e com o uso de imagens, indicando a concentração dos níveis de calor em determinadas regiões. O conhecimento geomorfológico localiza na averiguação da paisagem um enfoque integrador e sistêmico do espaço geográfico, envolvendo as formas de relevo, os processos dinâmicos e as atividades antrópicas, dentro da cultura social influente junto à natureza.

Analisar a relação entre os aspectos naturais da paisagem geomorfológica com os impactos antrópicos no solo do município de Juazeiro do Norte, pode evidenciar as formas de degradação causadas pela urbanização e suas consequências socioambientais, como a formação da Ilha de Calor. 
Id on Line Revista Multidisciplinar e de Psicologia

Id on Line Multidisciplinary and Psycology Journal

\title{
Metodologia
}

\section{Tipo de Estudo}

Na construção do projeto de pesquisa foi levantada a problemática e a hipótese para fundamentação inicial da revisão bibliográfica e definição dos objetivos. Foram pesquisados trabalhos sobre ilhas de calor, sustentabilidade, aquecimento urbano, poluição atmosférica, desenvolvimento urbano e as características geográficas e urbanas da cidade de Juazeiro do Norte - CE.

Posteriormente foi desenvolvido o estudo de caso, com abordagem descritiva que armazena, avalia e relaciona os eventos ou fenômenos mutáveis sem manipular suas informações (TOGATLIAN, 2004).

O estudo de caso qualitativo e/ou quantitativo, um objeto de pesquisa (programa, espaço, unidade social, grupo de pessoas ou uma pessoa), descrevendo a problemática, investigando as características e testando metodologias para evidenciar resoluções pela avaliação teórica e prática das propriedades (RODRIGO, 2008).

\begin{abstract}
Pesquisas de natureza qualitativa envolvem uma grande variedade de materiais empíricos, que podem ser estudos de caso, experiências pessoais, histórias de vida, relatos de introspecções, produções e artefatos culturais, interações, enfim, materiais que descrevam a rotina e os significados da vida humana em grupos. Esta abordagem qualitativa tem sido apresentada como soft science $e^{5}$, principalmente por aqueles que adotam posições positivistas, assumindo que a realidade social seja estável e imutável, o que a tornaria candidata a estudos de natureza quantitativa que ofereceriam maiores oportunidades para explicação e generalização de resultados (DENZIN e LINCOLN, 2000 apud CESAR, 2005, p. 02).
\end{abstract}

Dessa forma, os objetivos do estudo de caso é a interpretação do contexto, as ações, problemática da situação e multiplicidade do fato, observando o caso, os dados e os resultados aferidos (RODRIGO, 2008).

No presente estudo, foi abordado um espaço geográfico regional visando identificar qualitativamente e quantitativamente sua condição e perfil climático. Segundo, Cesar (2005, p. 04) “a utilização de uma amostra é apropriada para determinar se corretas as proposições

\footnotetext{
${ }^{5}$ Termo coloquial utilizado para comparar os campos científicos com base na percepção do rigor metodológico e legitimidade. Nesse caso a soft Science (ciência macia), refere-se a utilização de teorias clássicas para explicar os desdobramentos atuais nos diversos setores do conhecimento. 
teóricas, pois permite o acesso a informações não facilmente disponíveis em amostras mais complexas".

\section{Local, Objeto e Período do Estudo.}

O local e o objeto de estudo é a cidade de Juazeiro do Norte sendo realizada a elaboração do projeto de pesquisa entre janeiro de 2013 a abril de 2013, e a coleta dos dados para compor o resultado no mês de outubro de 2013.

\section{Coleta de Dados e Avaliação}

A coleta de dados para compor os resultados do estudo foi realizada com base nos dados do Instituto Nacional de Meteorologia de 2013.

\section{Resultados e Discussões}

A dinâmica social presente no espaço ambiental, seja global ou regional, ocasiona o aparecimento de novas condições climáticas e alterações nos ecossistemas existentes. Essas alterações ou condições estimulam o aparecimento e instalação de Ilhas de Calor, que trazem consequências diretas ao espaço acometido.

Ao avaliar o aparecimento do fenômeno climático é necessário considerar às variações de temperatura que ocorrem na cidade, assim deve-se analisar a amplitude térmica como importante parâmetro de indicação para formação da Ilha de Calor. 
Id on Line Revista Multidisciplinar e de Psicologia

Id on Line Multidisciplinary and Psycology Journal

Segundo o Instituto Nacional de Meteorologia (INM) a variação térmica registrada no período de Outubro de 2013, por meio da aferição das temperaturas máximas e mínimas diárias, demonstrou que a temperatura máxima se manteve constante na maior parte dos dias, com alterações nos dias 5 e 6; entre 11 e 17; 19 e 20; e, 26 e 27. Já os valores para mínima não sofreram grandes alterações no período como observado no gráfico das variações de temperatura para o mês de outubro de 2013 do INM, como disposto na Figura 3.

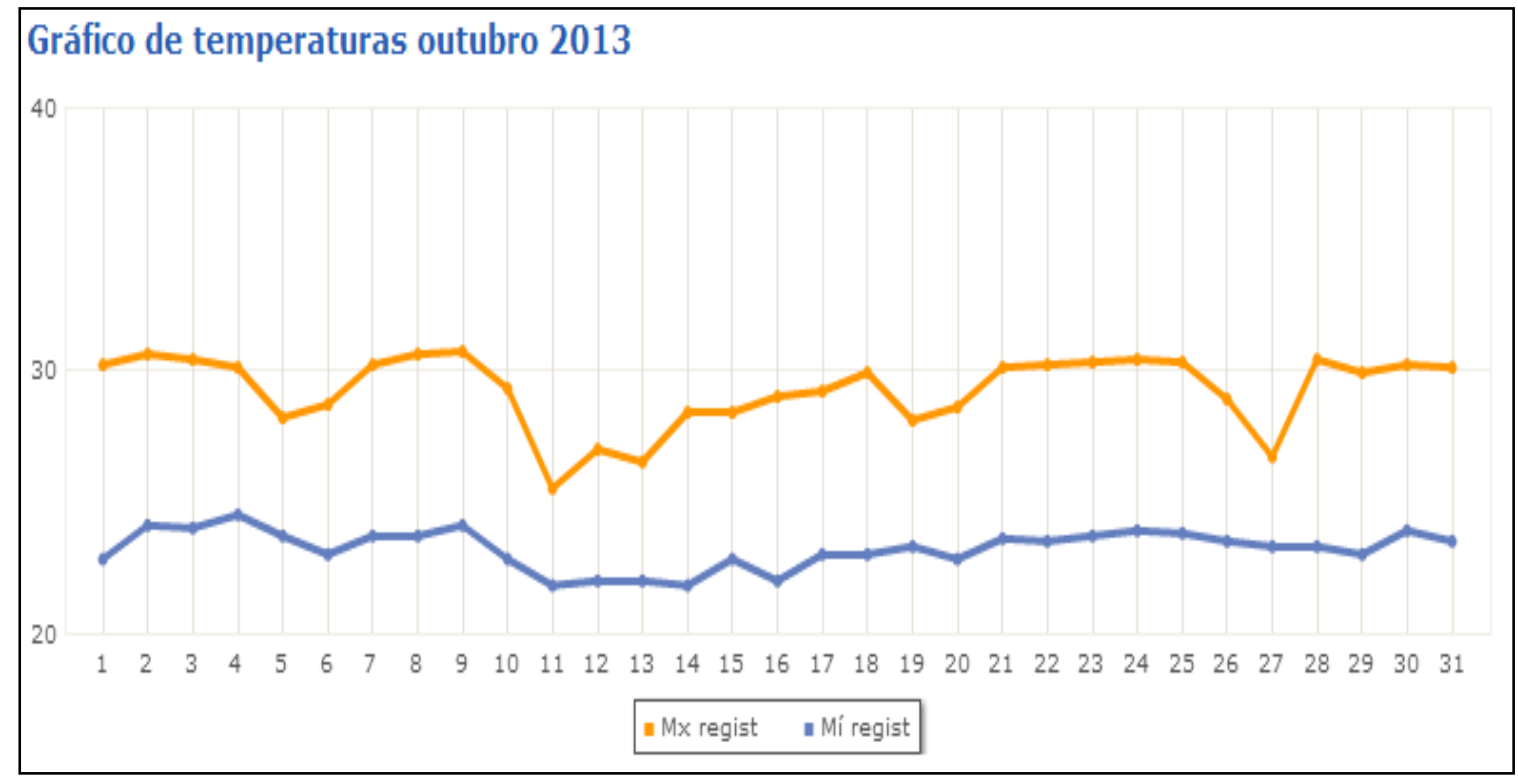

Figura 3: Gráfico de Temperaturas do Mês de Outubro de 2013.

Fonte: Instituto Nacional de Meteorologia. Disponível em www.inmet.gov.br/, acesso em 15/11/2013.

A expressão Amplitude Térmica designa a diferença entre a temperatura máxima e a temperatura mínima registada num determinado período de tempo. Esta informação é normalmente utilizada na investigação da atmosfera em uma determinada área geográfica. Em geral, climas continentais ou das zonas interiores tende a produzir fortes oscilações térmicas, tanto diárias quanto anuais o que se verifica em Juazeiro do Norte quando ao analisar o gráfico de temperaturas no recorte temporal de outubro de 2013, disposto na figura 4. Logo, a temperatura é um parâmetro físico descritivo importante para a análise do sistema atmosférico de Juazeiro do Norte. 
Id on Line Revista Multidisciplinar e de Psicologia

Id on Line Multidisciplinary and Psycology Journal

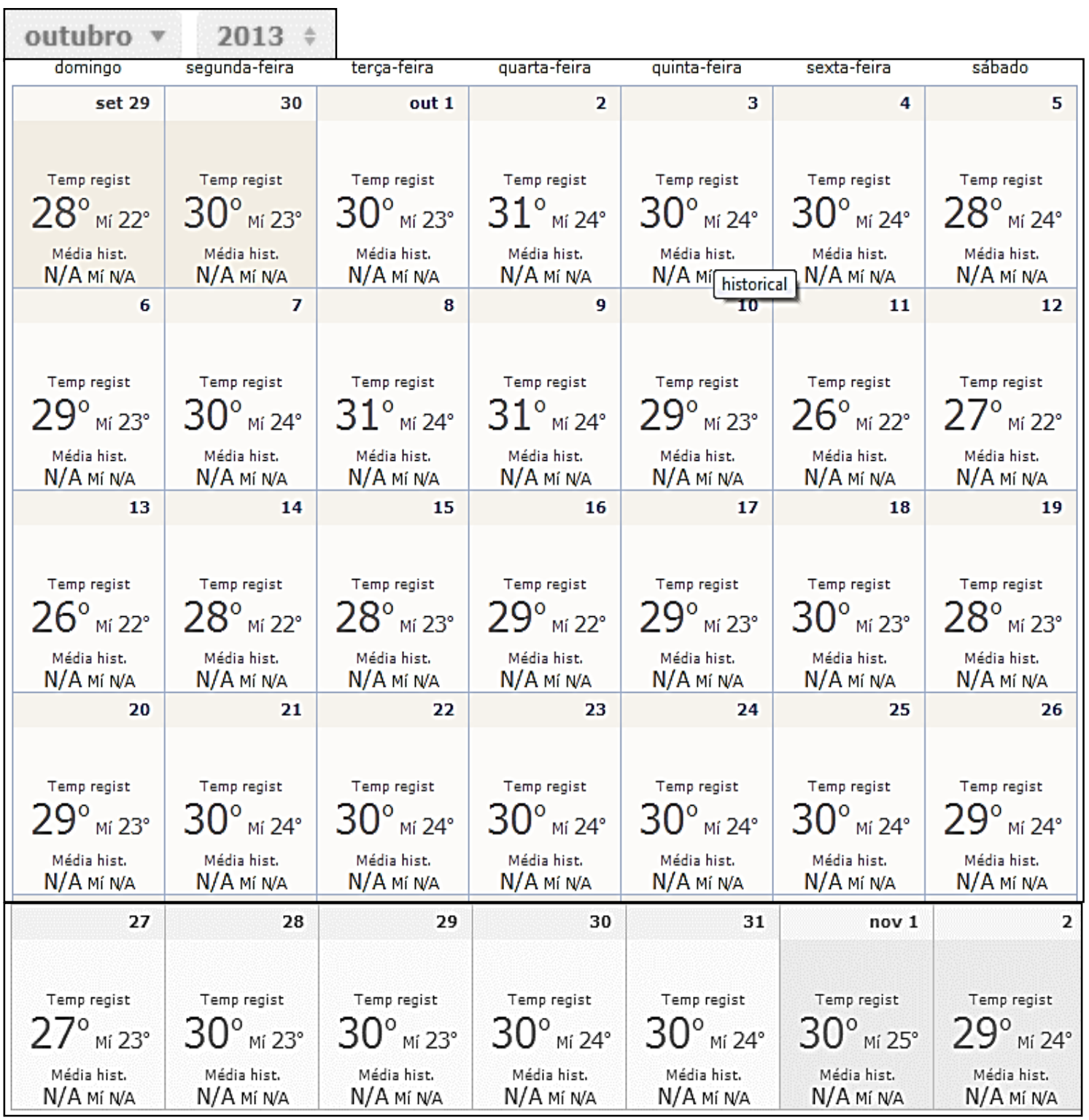

Figura 4: Temperaturas máximas e mínimas diárias do mês de Outubro/2013 em Juazeiro do Norte.

Fonte: Disponível em www.climatempo.com.br/previsao-dotempo/cidade/.../juazeirodonorte, acesso em $15 / 11 / 2013$.

A cidade de Juazeiro do Norte possui 34 bairros. As zonas periféricas escolhidas para aferir as temperaturas máximas e mínimas foram os bairros São José e Aeroporto devido aos seguintes critérios de localização: situam-se no eixo longitudinal, longe da região central da cidade e são geograficamente opostos, permitindo melhor análise das condições climáticas da cidade. 


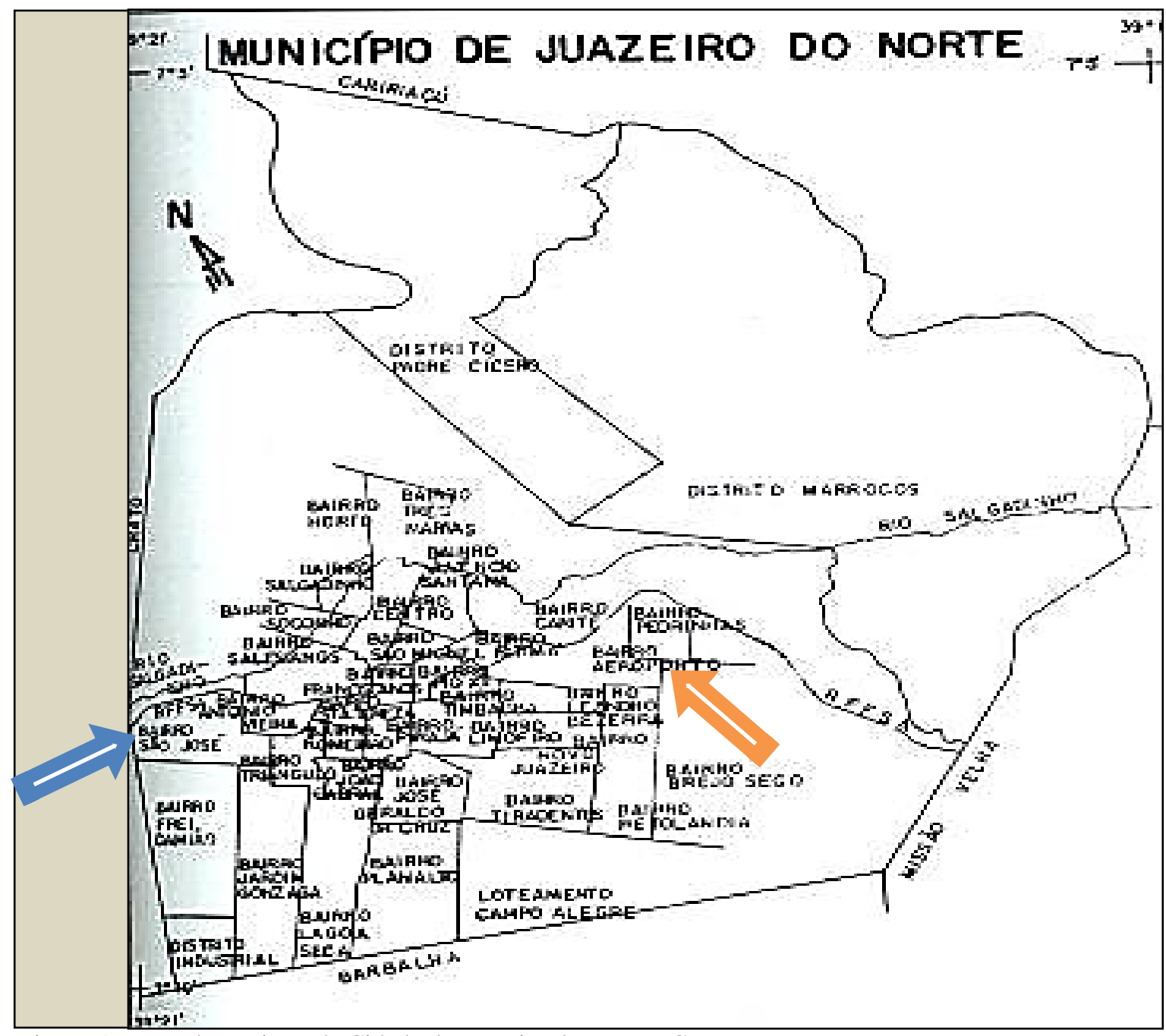

Figura 5: Mapa dos Bairros da Cidade de Juazeiro do Norte - CE.

Fonte: Google Mapas, Disponível em www.google.com/maps, acesso em 15/11/2013.

Ao avaliar a presença do fenômeno climático em uma urbe é necessário considerar o clima, área, ocupação demográfica e atividades socioeconômicas da cidade. Além disso, devese analisar a temperatura das zonas periféricas para detectar possíveis diferenças de temperatura entre o espaço adjacente e núcleo citadino, as quais muitas vezes, devem-se aos fatores físicos da ocupação do solo (AMORIM, 2007).

As altas temperaturas no centro da cidade em relação à periferia ou área rural condiciona um fenômeno climático que está diretamente ligado às condições estruturais, sociais e atividades econômicas presentes na unidade urbana.

O mês de Outubro foi escolhido por ser posterior a Agosto, considerado, geralmente, época mais quente na cidade. E, ainda, por ser Outubro, anterior ao período 
Id on Line Revista Multidisciplinar e de Psicologia

Id on Line Multidisciplinary and Psycology Journal

chuvoso. Isso porque, essa condição para aferição das temperaturas, pode demonstrar a presença do fenômeno sem a influência direta do calor ou do frio, apresentando maior crivo para o estudo.

Durante a pesquisa de campo, realizada em 29 e 30 de outubro de 2013, o material utilizado para medição das amplitudes foi um psicrômetro giratório SP-G2 - IOPE, o psicrômetro giratório é construído em base de metal cromado, cabo de plástico resistente a impacto com articulação para dobrar. Com dois termômetros de precisão, escala interna de vidro opalino, graduação -10 a $+50^{\circ} \mathrm{C}$ com subdivisão $0,2^{\circ} \mathrm{C}$, colunas de mercúrio sendo uma de bulbo seco e outra de bulbo úmido, contendo na extremidade material para retenção de água. Exatidão +/- $1 \%$ da leitura. Fornecido com tabela psicrométrica. Peso de 650g.

As medições foram realizadas em 29 e 30 de outubro de 2013 no intervalo de tempo entre as $11 \mathrm{~h} 00 \mathrm{~min}$ da manhã e $13 \mathrm{~h} 00 \mathrm{~min}$ da tarde, O horário escolhido deve-se pelo fato da maior parte do espectro ultra violeta que chega à superfície terrestre, a radiação UVA (comprimento de onda entre 315 a $400 \mathrm{~nm}$ ) possui intensidade constante durante todo o ano, entretanto essa intensidade é maior entre 10 e 16 horas que nos outros horários.

Após a medição da temperatura nas áreas periféricas escolhidas os valores encontrados foram comparados aos valores aferidos na região central da cidade (Tabela 1).

\begin{tabular}{|c|c|c|c|c|c|c|c|c|}
\hline $\begin{array}{c}\text { JUAZEIRO DO } \\
\text { NORTE }\end{array}$ & \multicolumn{2}{|c|}{$\begin{array}{l}\text { BAIRRO } \\
\text { SÃO JOSÉ }\end{array}$} & \multicolumn{2}{|c|}{ CENTRO } & \multicolumn{2}{|c|}{$\begin{array}{c}\text { BAIRRO } \\
\text { AEROPORTO }\end{array}$} & \multicolumn{2}{|c|}{ CENTRO } \\
\hline $\begin{array}{l}\text { TEMPERATURA } \\
\left({ }^{\circ} \mathrm{C}\right)\end{array}$ & $\underline{29 / 10}$ & $\underline{30 / 10}$ & $\underline{29 / 10}$ & $\underline{30 / 10}$ & $29 / 10$ & $\underline{30 / 10}$ & $\underline{29 / 10}$ & $\underline{30 / 10}$ \\
\hline MÁXIMA & $27^{\circ}$ & $28^{\circ}$ & $30^{\circ}$ & $30^{\circ}$ & $26^{\circ}$ & $27^{\circ}$ & $30^{\circ}$ & $30^{\circ}$ \\
\hline MÍNIMA & $22^{\circ}$ & $23^{\circ}$ & $23^{\circ}$ & $24^{\circ}$ & $22^{\circ}$ & $23^{\circ}$ & $23^{\circ}$ & $24^{\circ}$ \\
\hline DIFERENÇA & $5^{\circ}$ & $5^{\circ}$ & $7^{\circ}$ & $6^{\circ}$ & $4^{o}$ & $4^{o}$ & $7^{o}$ & $6^{o}$ \\
\hline
\end{tabular}

Tabela 1: Temperaturas máximas, mínimas e diferença térmica entre os pontos Fonte: Pesquisa direta, 2013. 
Id on Line Revista Multidisciplinar e de Psicologia

Id on Line Multidisciplinary and Psycology Journal

A falta de planejamento urbano, o rápido desenvolvimento econômico e a industrialização desenfreada podem desencadear inúmeros problemas socioambientais e alterações climáticas aos espaços urbanos, como aumento demasiado da temperatura nas zonas centrais, que são mais densamente populosas, e apresentam alta dinâmica social e econômica. Segundo Ana Fani (2004, p. 07),

\begin{abstract}
Esta análise envolve riscos de simplificação da realidade, pois a sistematização ao evitar o diferente desemboca, necessariamente, na busca de uma harmonia que ignora as contradições profundas sob as quais se deve analisar as atuais relações cidade/campo no Brasil. Como decorrência, a análise desemboca no óbvio: a busca do "desenvolvimento sustentável", como caminho único possível de resolver os desequilíbrios. Aqui, a busca do equilíbrio, harmonia e coerência confunde, inexoravelmente, desenvolvimento com crescimento". Como consequência o ecossistema desequilibrado em função das ações que degradam a qualidade ambiental, requer um equilíbrio baseado na eficácia do que chama "desenvolvimento sustentável" e aparece como ideologia que elimina conflitos e contradições (CARLOS, 2004, p. 07).
\end{abstract}

Cidades com acelerado desenvolvimento urbano, como Juazeiro do Norte, estão propensas a problemas socioambientais, alterações térmicas e mudanças geográficas, considerando que a ocorrência das ilhas de calor não é condição exclusiva das metrópoles podendo estar presentes em aglomerados urbanos em ascensão.

A Radiação Solar que incide sobre a superfície da Terra interage com vários elementos que a compõe. Essa relação possibilita, não só a iluminação natural, mas também o ganho de calor. As edificações na cidade potencializam esse ganho de calor alterando a rugosidade, a forma do relevo e a impermeabilização do solo.

Esta pesquisa mostrou resultados importantes sobre as características da temperatura do ar nas áreas urbanas de Juazeiro do Norte. Tanto nos bairros mais afastados do centro, como no próprio centro da cidade, foram constatadas diferenças térmicas comparandose os dados entre si. Garcia (1996, p. 285), classificou as diferenças térmicas em ilhas de calor de fraca magnitude quando as diferenças variam de $0^{\circ} \mathrm{C}$ a $2^{\circ} \mathrm{C}$, média magnitude quando variam de $2^{\circ} \mathrm{C}$ a $4^{\circ} \mathrm{C}$, forte magnitude quando variam de $4^{\circ} \mathrm{C}$ a $6^{\circ} \mathrm{C}$ e de muito forte quando superiores a $6^{\circ} \mathrm{C}$.

As medições de temperaturas máximas e mínimas foram feitas nos dias 29 e 30 de outubro de 2013, as maiores diferenças de temperatura foram registradas no dia 29 e comparando-se as temperaturas do Bairro São José com o centro neste dia temos uma diferença de $2^{\circ}$, realizando a mesma comparação, entretanto com o Bairro Aeroporto, a diferença é de $3^{\circ}$, 
Id on Line Revista Multidisciplinar e de Psicologia

Id on Line Multidisciplinary and Psycology Journal

o que se constata de acordo com Garcia (1996, p. 285) é que em Juazeiro do Norte há a formação de uma Ilha de Calor de média intensidade, pois a cidade apresentou diferenças térmicas intraurbanas que chegou a $3^{\circ} \mathrm{C}$.

A área central densamente construída foi também a que apresentou maior temperatura. O núcleo das maiores temperaturas ocorreu na Avenida principal (Padre Cícero) que é também uma rodovia que passa no meio da cidade. Neste local também se concentra o comércio e a densidade de vegetação arbórea nas ruas é baixa. A malha urbana de Juazeiro do Norte vem se concretizando sem que haja um planejamento urbano que estabeleça limites a questão da valorização do solo urbano pressionado pelo mercado imobiliário.

As consequências deste processo são a degradação das condições de ventilação; aumento de intensidade da ilha de calor urbano e concentração da produção de origem antrópica e diminuição da cobertura vegetal. Jendritzky (1993) considera que a ilha de calor urbano é sem dúvida relevante para a saúde humana, pelo que o planejamento urbano deve ter, como um dos seus principais objetivos a sua mitigação.

\section{Considerações Finais}

O desenvolvimento e as formas de ocupação e utilização do espaço urbano podem determinar condições favoráveis ou desfavoráveis à própria categoria urbana nos aspectos referentes às características da atividade humana e ambiental. Tais condições podem ser facilmente encontradas em cidades com núcleos urbanos em intenso desenvolvimento. Com isso, determinar a ocorrência de desequilíbrios ambientais no núcleo urbano pode, quem sabe, permitir a identificação de caminhos acessíveis que possibilitem o saneamento das condições estruturais e funcionais que propiciem tal desequilíbrio climático, permitindo a organização dos núcleos urbanos.

Dessa forma, foi desenvolvimento o estudo no município de Juazeiro do Norte devido às características térmicas, à ocupação dos espaços, fluxo veicular e distribuição espacial da população, considerando o desenvolvimento urbano intenso que apresenta condições favoráveis para o surgimento de problemas ambientais como a Ilha de Calor. Não obstante, o estudo do fenômeno, causas e consequências pode auxiliar no saneamento dos desequilíbrios 
Id on Line Revista Multidisciplinar e de Psicologia

Id on Line Multidisciplinary and Psycology Journal

estruturais e ambientais encontrados, permitindo o planejamento e estruturação da unidade municipal.

Referências

ALCOFORADO, M. J., et al. A ilha de calor de Lisboa. Aquisição de dados e primeiros resultados estatísticos para aplicação ao ordenamento urbano. Centro de estudos geográficos universidade de Lisboa. Geophilis - o sentir e os sentidos da geografia, lisboa, pp 593-612, ceg 2007.

AMORIM, M. C. de C. T. A geração do clima urbano em cidades do oeste do estado de São Paulo/Brasil.FCT - Presidente Prudente - SP, p. 01-12, 2009.

BASANE, A. C. et al. A influência do clima urbano em cidades de pequeno porte: uma revisão teórica. I Simpósio de Estudos Urbanos. 29 a 31 de Agosto de 2011.

BIAS, E. de S.; BAPTISTA, G. M. de M.; LOMBARDO, M. A. Análise do fenômeno de ilhas de calor urbanas, por meio da combinação de dados landsat e ikonos.Anais XI SBSR, Belo Horizonte, Brasil, 05 -, INPE, p. 1741 - 1748, 10 abril 2003.

BURALI, J. B. Aquecimento Global: O clima de extremos. Coordenadora Acadêmica XIV CONOSUR \& XIII ENERI. Publicado no Jornal Folha de São Paulo, em 18 de novembro de 2007

CDL. Câmara de Dirigentes Lojistas de Juazeiro do Norte - CE. Disponível em: http://www.cdljuazeirodonorte.org.br/, acesso em: 09/04/2013.

CELESTINO, P. L. Proposta: av. Perimetral Paulo Maia ligando Juazeiro ao Crato. Cidade Juá. 13 de julho de 2011. Disponível em: http://www.cidadejua.com/2011/07/proposta-avperimetral-paulo-maia.html, acesso em 09/04/2013.

CERVO, A. 1., BERVIAN, P. A. Metodologia Científica. $5^{\circ}$ ed. - São Paulo: Pearson Prentice Hall, 2002

CESAR, A. M. R. V. C. Método do Estudo de Caso (Case Studies) ou Método do Caso (Teaching Cases)? Uma análise dos dois métodos no Ensino e Pesquisa em Administração, 2005.

HONORATO, A. F. A.; ANDRADE, V. S. da A. Ilhas de calor e frescor na área urbana da cidade deAquidauana-MS. Revista Geonorte, edição especial, V.2, N.4, p.878 - 886, 2012. 
Id on Line Revista Multidisciplinar e de Psicologia

Id on Line Multidisciplinary and Psycology Journal

IBGE Cidades, $2012 . \quad$ Disponível em http://www.ibge.gov.br/home/estatistica/populacao/estimativa2012. Acesso em 01 de abril de 2013.

IPECE (Instituto de Pesquisa e Estratégia Econômica do Ceará). Juazeiro do norte: perfil básico do município. FORTALEZA/CE. 2012. Disponível em http://www.ipece.ce.gov.br/publicacoes/ipece-

informe/Ipece_Informe_22_dezembro_2011.pdf, Acesso em 01/04/2013.

LIMA, G. G. de; RIBEIRO, S. C.. Geomorfologia e paisagem do município de Juazeiro do Norte/CE: relações entre a natureza semi-árida e os impactos antrópicos.REVISTA GEONORTE, Edição Especial, V.2, N.4, p.520 - 530, 2012.

LOPES, J. Juazeiro do Norte-CE: Indústria calçadista polo avança em tecnologia. Portal Cariri Notícia, 26/06/2011. Disponível em: http://www.caririnoticia.com.br/2011/06/juazeirodo-norte-ce-industria-calcadista-polo-avanca-em-tecnologia.html, acesso em 09/04/2013.

MAY, LUSTOSA e VINHA. Economia do Meio Ambiente. São Paulo: Editora Elsevier, 2003.

PREFEITURA MUNICIPAL DE JUAZEIRO DO NORTE, CE. Disponível em: http://www.juazeiro.ce.gov.br/, acesso em 09/04/2013.

RODRIGO, J. Estudo de caso: Fundamentação Teórica. Vestcon, 2008.

SCHIER, R. A. Trajetórias do conceito de paisagem na geografia.Trajectories of the concept of landscape in geography. R. RA'E GA, Curitiba, n. 7, p. 79-85, Editora UFPR, 2003.

SILVA, B. C. N.; COELHO, A. S. Macrocefalia urbana em Roraima e sua Repercussão nos serviços de saúde.Rde - revista de desenvolvimento econômico. Ano VIII, nº 13, Salvador, BA, Janeiro de 2006.

TEZA, C. T. V.; BAPTISTA, G. M. de M. Identificação do fenômeno ilhas urbanas de calor por meio de dados ASTER on demand 08 - Kinetic Temperature (III): metrópoles brasileiras. Anais XII Simpósio Brasileiro de Sensoriamento Remoto, Goiânia, Brasil, INPE, p. 3911-3918, 16-21 abril 2005.

TOGatlian, M. A. Tipos de Pesquisa. 2004. Disponível em: http://www.togatlian.pro.br/docs/pos/unesa/tipos.pdf, acesso em 23/01/2013.

Como citar este artigo (Formato ABNT):

FRANCA, G.L. Condições climáticas em Juazeiro do Norte - CE: A Formação de Ilha de Calor. Id on Line Revista Multidisciplinar e de Psicologia, Out-Nov. de 2016, vol.10, n.31, Supl 3, p. 259-278. ISSN: 19811179.

Recebido: 08/11/2016

Aceito: 08/11/2016 